\title{
Evaluation of Three Evaporation Estimation Techniques In A Semi-Arid Region (Omar El Mukhtar Reservoir Sluge, Libya- As a case Study)
}

\author{
Lubna s. Ben Taher* \\ Civil Eng. Dept., Univ. of Benghazi, Libya.
}

\begin{tabular}{l} 
A R T I C L E I N F O \\
\hline Article history: \\
Received: 15 January, 2017 \\
Accepted: 06 February, 2017 \\
Online: 25 February, 2017 \\
\hline Keywords: \\
Modeling, Evaporation \\
Omar El Mukhtar Reservoir \\
Semi-arid region \\
Assessment \\
ANN \\
RSM
\end{tabular}

\section{Introduction}

Evaporation is one of major components of the hydrologic cycle and it describes the loss of water from water bodies to the air over a long period to elucidate its relationship with annual precipitation. Estimation of evaporation rate is important in the study of hydrology, climate, agricultural water system, design and operation of irrigation systems. Many methods for estimation of evaporation losses from free water surfaces were reported and it can be divided into several categories including: (Empirical Methods, Water Budget Methods, Energy Budget Methods ,MassTransfer Methods and Combination Methods) [1]. Accurate and reliable measurement of evaporation for a long term has been investigated by researchers. In deceit, an observation from Class A Pan evaporimeter and contemporary correlation techniques were used, in indirect methods, the evaporation is estimated from other meteorological variables like temperature, wind speed, relative humidity and solar radiation.

*Corresponding Author: Lubna s. Ben Taher, Univ. of Benghazi, Libya. Email: Lina7981@yahoo.com
Recently, the advanced soft computing techniques have been successfully applied for modeling of hydrological data due to their ability to learn complex and non-linear relations .

In their study [2], the evaporation from Batu Dam Reservoir which is located at the Selangor state, Malaysia was estimated using artificial neural networks (ANN) and climate based models (Penman and Priestley-Taylor). The models output display that ANN-4 model was the best with the coefficient of efficiency (E) of $90 \%$.

In [3], they studied, daily evaporation prediction were prepared by Penman equation, Levenberg-Marquardt algorithm based on "Feed Forward Back Propagation Artificial Neural Networks (LMANN)", radial basis neural networks (RBNN), generalized regression neural networks (GRNN). noticed that the results of neural network models were statistically more meaningful than the Penman equation.

At their investigation (ANN), Least Squares - Support Vector Regression (LS-SVR), Fuzzy Logic, and Adaptive Neuro-Fuzzy Inference System (ANFIS) techniques improve the accuracy of daily pan evaporation estimation in sub-tropical climates [4]. Meteorological data from the Karso watershed in India (consisting 
of 3801 daily records from the year 2000 to 2010) were used. Based on the comparison, it was found that the Fuzzy Logic and LS-SVR approaches can be employed successfully in modeling the daily evaporation process from the available climatic data.

In [5] the authors used the response surface method (RSM) to extend estimation of monthly pan evaporations using high-order response surface (HORS) function. A HORS function was proposed to improve the accurate predictions with various climatic data, from two stations, Antalya and Mersin, in Mediterranean Region of Turkey. The HORS predictions were compared to artificial neural networks (ANN), neuro-fuzzy (ANFIS) and fuzzy genetic (FG) methods in these stations. Comparison results indicated that HORS models performed slightly better than FG, ANN and ANFIS models.

In [6], the authors investigate the abilities of six different soft computing methods, Multi-layer perceptron (MLP), generalized regression neural network (GRNN), fuzzy genetic (FG), least square support vector machine (LSSVM), multivariate adaptive regression spline (MARS), adaptive neuro-fuzzy inference systems with grid partition (ANFIS-GP), and two regression methods, multiple linear regression (MLR) and Stephens and Stewart model (SS) in predicting monthly Ep. Long-term climatic data at eight stations in different climates, during 1961-2000 were used . The accuracies of above models ranked as: MLP, GRNN, LSSVM, FG, ANFIS-GP, MARS and MLR. Generalized models were also developed and tested with data of eight stations.

The situation in Libya is typical of semi-arid climate, with average annual rainfall of less than $(100 \mathrm{~mm}$ )and average annual evaporation is estimated to be $(2500 \mathrm{~mm})$ which is much higher than the rainfall [7]. This highlights the seriousness of water losses problem from open water bodies. In the Great-Man-Made-RiverProject there are many of this type of open reservoirs, such as the Omar Muktar Open Reservoir. Over 20\% of the total Omar Muktar Open Reservoir's water storage capacity, $\left(4.7 \mathrm{Mm}^{3}\right)$, is lost due to the evaporation phenomena.

Thus, the objectives of this study are to assess the estimates of the evaporation using three techniques against observed evaporation values for Omar Mukhtar Reservoir which is located in semi -arid region. Investigation of the capability and usability of three different soft computing methods, artificial neural networks (ANN), Multiple linear regression (MLR) and response surface methods (RSM) in modeling of the monthly evaporation(Evp.) for Omar Mukhtar open Reservoir. The meteorological data used to estimate the evaporation was acquired from the meteorological observatory included : average air temperature $\left(\right.$ Temp. $\left.\mathrm{C}^{0}\right)$, relative humidity (Rh.\%), atmospheric pressure (Pa. Pas), wind speed (Ws. Knot), sunshine hours (sh. hr), rainfall (Rf. mm) . The evaporation from the pan was multiplied by a factor of (0.73) to get the actual evaporation. Eight years of monthly evaporation recorded from 2001 to 2009 (108 value) were used to in this study. The model performances was compared and discussed through: estimating ( Evp.) of each month using ANN, MLR, and RSM models. This will be the first study to compare the accuracy of multiple soft computing models (Evp.) estimation for open reservoir (Omar El Mukhtar) at semi-arid climates.

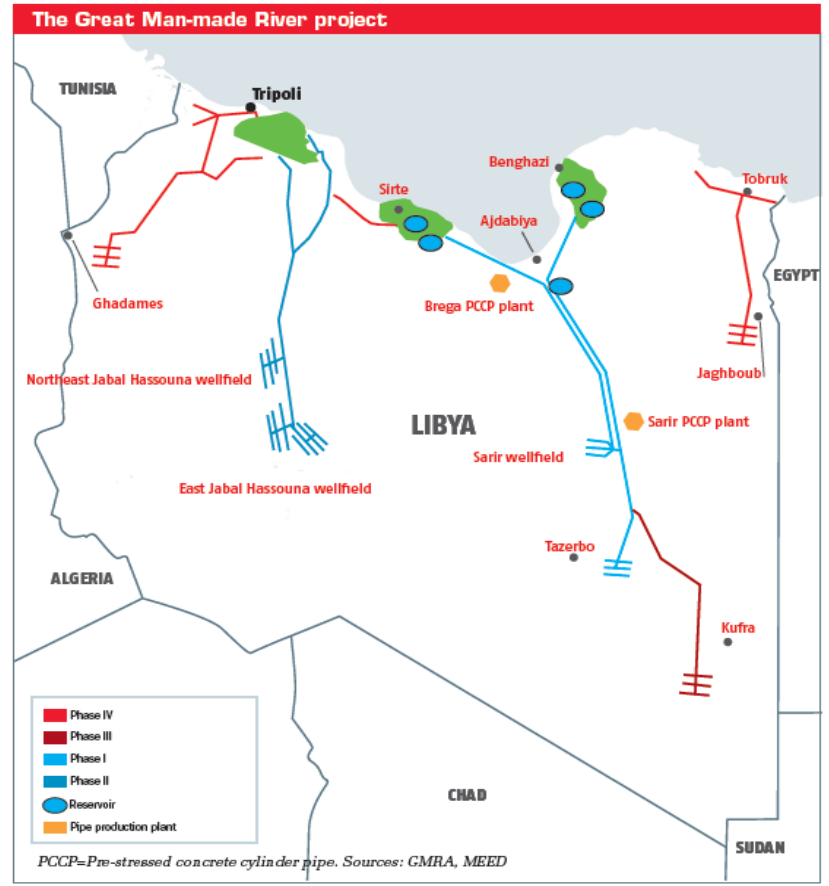

Figure 1 The man made river map.

\section{2- Materials And Methodology}

\subsection{Study Area:}

Omar El Mukhtar tank is located at a distance of $(45 \mathrm{Km})$ from the south-east of the city of Benghazi. Create reservoir in the form of free rock fill dam circular shape up $(9 \mathrm{~m})$ and a length of (3.2 $\mathrm{km})$ circumference; diameter up to $(960 \mathrm{~m})$ from the top as rise in the bottom of the tank from the surface level Sea about $(55 \mathrm{~m})$ and the maximum level of the run up to $(63.5 \mathrm{~m})$ from the surface level Sea, so that a total capacity of $\left(4.7 \mathrm{Mm}^{3}\right)$ of water, and spacessurface of the reservoir is approximately $\left(750,000 \mathrm{~m}^{2}\right)$ see Figure 1and 2. construct the reservoir layer clay sealing parasitic in nature, and to prevent leakage of water through the rock fill dam was a protective membrane.

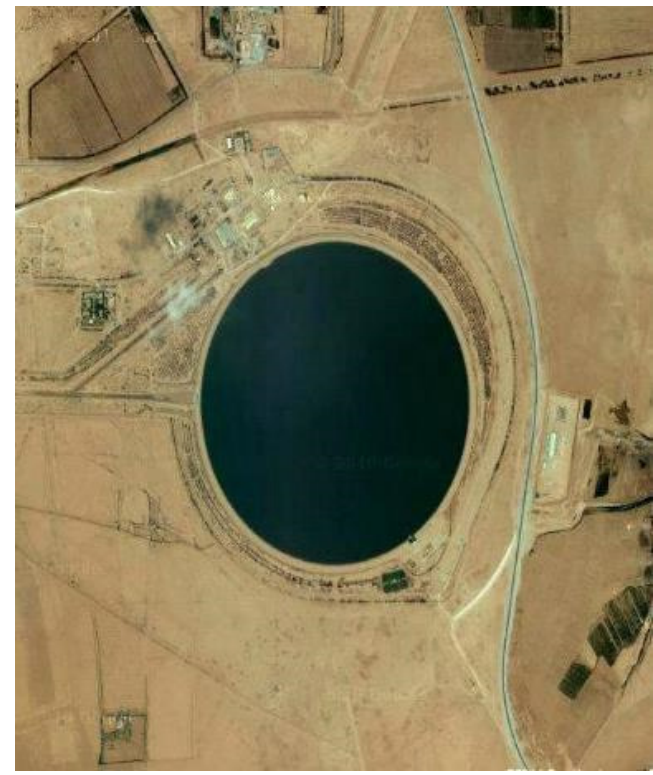

Figure 2 Omar El Mukhtar reservoir 


\subsection{Study Methodology:}

MLR is a technique utilized to model the linear relationship between a dependent variable and one or more independent variables. The dependent variable is sometimes additionally called the predictor. MLR is depended on least squares methods. The model is fit such that the sum of squares of differences of estimated and observed values is minimized. MLR probably the most widely used method in hydrology and climatology for developing models to reconstruct or analysis the long-term variations of climatic factors.

MINITAB software programing omits all observations that contain missing values in the response or in the predictors, from calculations of the regression equation and the ANOVA table items. By default, a y-intercept term is included in equation. Thus, MINITAB fits the model However, if the response at $x=0$ is naturally zero, a model without an intercept can make sense. If so, choose to not fit an intercept, and the $\beta_{0}$ term will be omitted. Equation 1 provide the general formula for MLR:

$$
y=\beta_{0}+\beta_{1} x_{1}+\beta_{2} x_{2}+------+\beta_{k} x_{n}+\in-1
$$

Where:

$\mathrm{y}=$ the predicted value (Evp. )

$\mathrm{x}_{1}, \mathrm{x}_{2},---\mathrm{x}_{\mathrm{n}}=$ the inputs ( Temp, Rh,--etc.)

$\beta_{0}, \beta_{1}, \beta_{2}, \varepsilon=$ random error representing the combined effects of variables

Response surface methodology (RSM) consists of a set of statistical methods that can be used to develop, improve, or optimize products. RSM typically is used in situations where several factors influence one or more performance characteristics, or responses. There are three general steps that comprise (RSM): experiment design, modeling, and optimization. Choosing the design correctly will ensure that the response surface is fit in the most efficient manner. MINITAB provides central composite and Box-Behnken designs see Figure 3 .

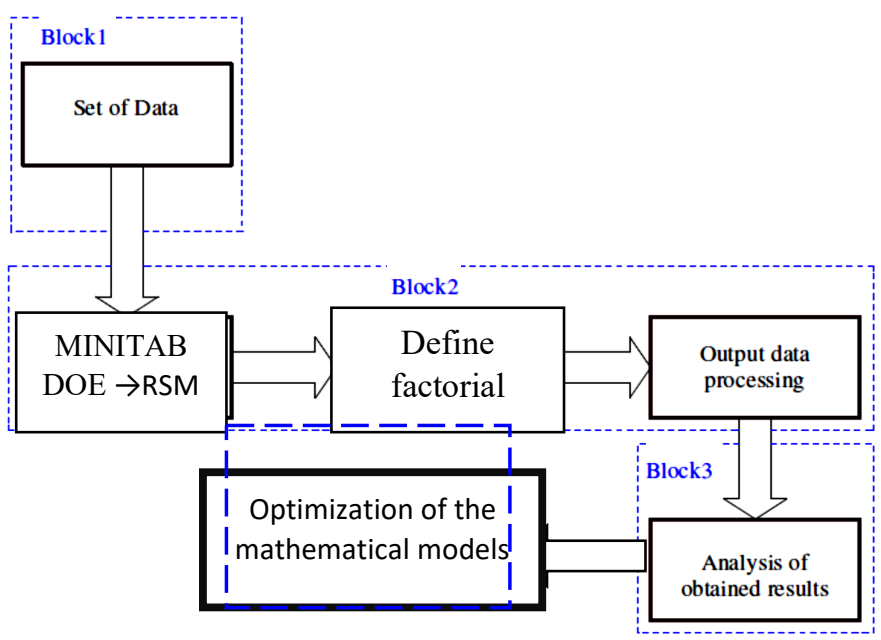

Figure 3. The RSM Diagram.
The empirical models were fit to the data, and polynomial models (linear or quadratic) typically were used. The Equation illustrates the general case of the full quadratic model for $\mathrm{k}=3$ as an example for independent variables see Equation .2:

$$
\begin{aligned}
\mathrm{y}= & \mathrm{b}_{0}+\mathrm{b}_{1} \mathrm{x}_{1}+\mathrm{b}_{2} \mathrm{x}_{2}+\mathrm{b}_{3} \mathrm{x}_{3}+\mathrm{b}_{12} \mathrm{x}_{1} \mathrm{x}_{2}+\mathrm{b}_{13} \mathrm{x}_{1} \mathrm{x}_{3} \\
& +b_{23} x_{2} x_{3}+b_{11} x_{1}^{2}+b_{22} x_{2}^{2}+b_{33} x_{3}^{2}+\mathrm{e}
\end{aligned}
$$

In this equation, the ten coefficients are represented by the $b_{k}$ and $\mathrm{e}$ is a random error term representing the combined effects of variables not included in the model. The interaction terms $\left(\mathrm{x}_{\mathrm{i}} \mathrm{x}_{\mathrm{j}}\right)$ and the quadratic terms $\left(\mathrm{x}_{\mathrm{i}}{ }^{2}\right)$ account for curvature in the response surface [8].

Artificial Neural Networks (ANN), are a form of computing inspired by the functioning of the brain and nervous system, and discussed in detail in a number of hydrologic papers [9]. The feed forward ANN has been adopted in many hydrological modeling studies because of its applicability to a variety of different problems [4]. Noted that more than one hidden layer may require in feed forward networks because a three-layer network can generate arbitrarily complex decision regions. Also, the appropriate input vector to the ANN model can be identified according to the procedure of the modeler. Back propagation is the most popular algorithm used for the training of the feed forward ANN. An objective function that considers both the ANN's structure and error, minimizes a linear combination of the resulting ANN's squared errors, weights, and biases in order to develop a less complex model at the end of training the resulting network has good generalization qualities.

The Levenberg-Marquardt (LM) training algorithm is a trust region based method with a hyper-spherical trust region [9]. This algorithm was implemented in this study using the Neural Network Toolbox of MATLAB, an example of Developed Structure of ANN with input combination as in Figure 4.

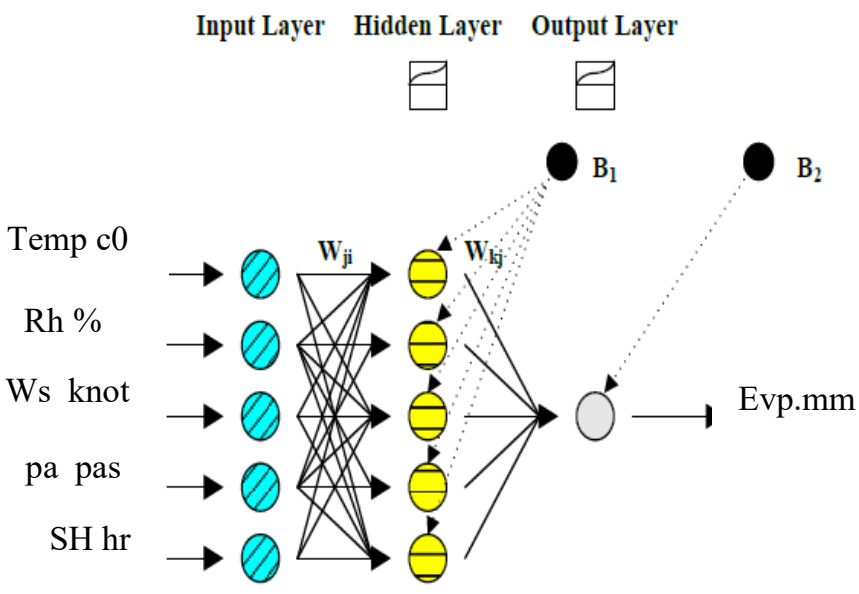

Figure 4. Developed Structure of ANN with input combination 5

\subsection{Comparative Statistics}


In this study, several statistical parameters were used to evaluate the performance of predicted models, which were given by the following relations [9]:

1- Mean absolute percentage error (MAPE\%)

$$
M A P E \%=\frac{100}{n} \sum_{t=1}^{n}\left|\frac{\text { Evp.obs. }- \text { Evp.pre. }}{\text { Evp.obs. }}\right| \quad-3
$$

\section{2- 95\% confidence limit (95CI\%):}

Standard error of the mean is given as

$$
S_{x}=\frac{s}{\sqrt{n-1}}
$$

The quantity ( Evp. - $\mu$ )/ $\mathrm{S}_{\mathrm{x}}$ has a t-distribution with $\mathrm{n}-1$ degrees of freedom, And for $95 \%$ confidence limit

Evp. $-1.95\left(\frac{\mathrm{s}}{\sqrt{\mathrm{n}-1}}\right)<\mu<$ Evp. $+1.95\left(\frac{\mathrm{s}}{\sqrt{\mathrm{n}-1}}\right) \quad-4$

The value on the left side of the inequality yields the lower limit, and on the right side yields the upper limit for the mean

3- E Efficiency factor:

$E=1-\left(\frac{\sum_{i=1}^{n}\left(E_{v p . o b s_{.}}-E_{\text {Evp.pre. }}\right)^{2}}{\sum_{i=1}^{n}\left(E_{v p . o b s ._{i}}-\overline{E v p . o b s .}\right)^{2}}\right)$

Where:

$\mathrm{n}=$ number of data

Evp.obs. $=$ observed evaporation data

Evp.pre.= predicted evaporation data

$\mathrm{S}=$ standard deviation

$\overline{\text { Evp.obs. }}=$ the mean of evaporation data.

A better fit, with zero indicating MAPE\% and high value of $\mathrm{E}$ a perfect prediction. Efficiency factor $(E=0$ to 1$)$ is calculated on the basis of the relationship between the predicted and observed mean deviations and it can show the correlation between the predicted and observed data. $\mathrm{E}$ is better suited to evaluate model goodness-of-fit than the $\mathrm{R}^{2}$ ( the square root of the correlation coefficient between the predicted and observed value). The probability of procedure produces an interval that contains the actual true parameter value is known as the Confidence Level and is generally chosen to be $95 \mathrm{CI} \%$. So the model if have a good performance well produce a results within the range of $95 \mathrm{CI} \%$ of the mean observed evaporation data. The models are used to generate evaporation data which conserve the main statistical characteristics of the historical data. This is verified through comparing values of mean, of generated evaporation data with those of historical data .

\section{Predicting Monthly Evaporations of Omar Muktar Open Reservoir:}

In this study, monthly climatic data at Omar Muktar Open Reservoir (is in the zone of semi-arid climate) were used for developing and testing Evp. models. Figure 5 shows the histogram distribution of the evaporation data with the basic statistical information details. The data used in this research cover 8 years (2001-2009) of monthly records of average air temperature (Temp. $\mathrm{c} 0)$, relative humidity ( $\mathrm{Rh} . \%$ ), atmospheric pressure (Pa. pas), wind speed (Ws. knot), sunshine hours (sh. hr), rainfall (Rf. mm) pan evaporation $\left(\right.$ Evp. $\mathrm{mm}^{3}$ ). Figures $6,7,8$, and 9 showing the variation of the evaporation to the climatic parameter using in this study. Table 1 showed the monthly of mean, standard deviation, minimum and maximum values of climatic parameters, respectively.

Table 1. The Statistical Data Information

\begin{tabular}{lcccc}
\hline Variable & Mean & StDev & Minimum & Maximum \\
\hline Temp max c0 & 25.29 & 5.791 & 15.2 & 33.8 \\
Temp min c0 & 15.541 & 4.929 & 7.1 & 24.6 \\
Rh \% & 63.361 & 8.224 & 38 & 80 \\
Ws knot & 11.838 & 1.742 & 7.5 & 17.1 \\
Sh hr & 9.069 & 2.339 & 3.89 & 12.95 \\
Pa pa & 999.75 & 8.39 & 925 & 1010.3 \\
Rf mm & 20.17 & 26.56 & 0 & 107.2 \\
Evp.mm & 98065 & 40358 & 7263 & 190039 \\
\hline
\end{tabular}

StDev, denote the standard deviation.
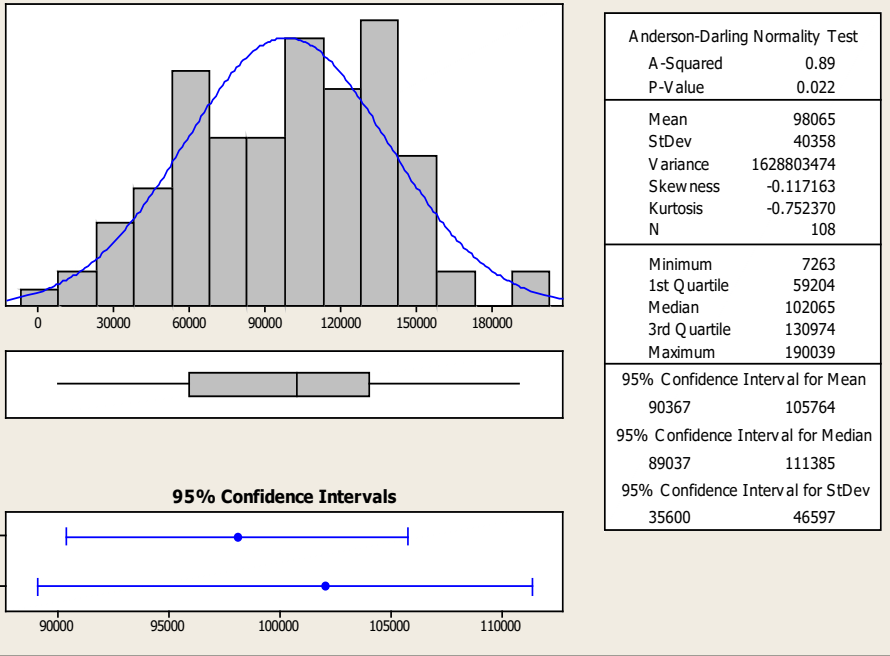

Figure 5 Monthly evaporation data mm3 for (2001 to 2009) at Omar Muktar Open Reservoir 
L.S. Bentaher / Advances in Science, Technology and Engineering Systems Journal Vol. 2, No. 2, 19-29 (2017)
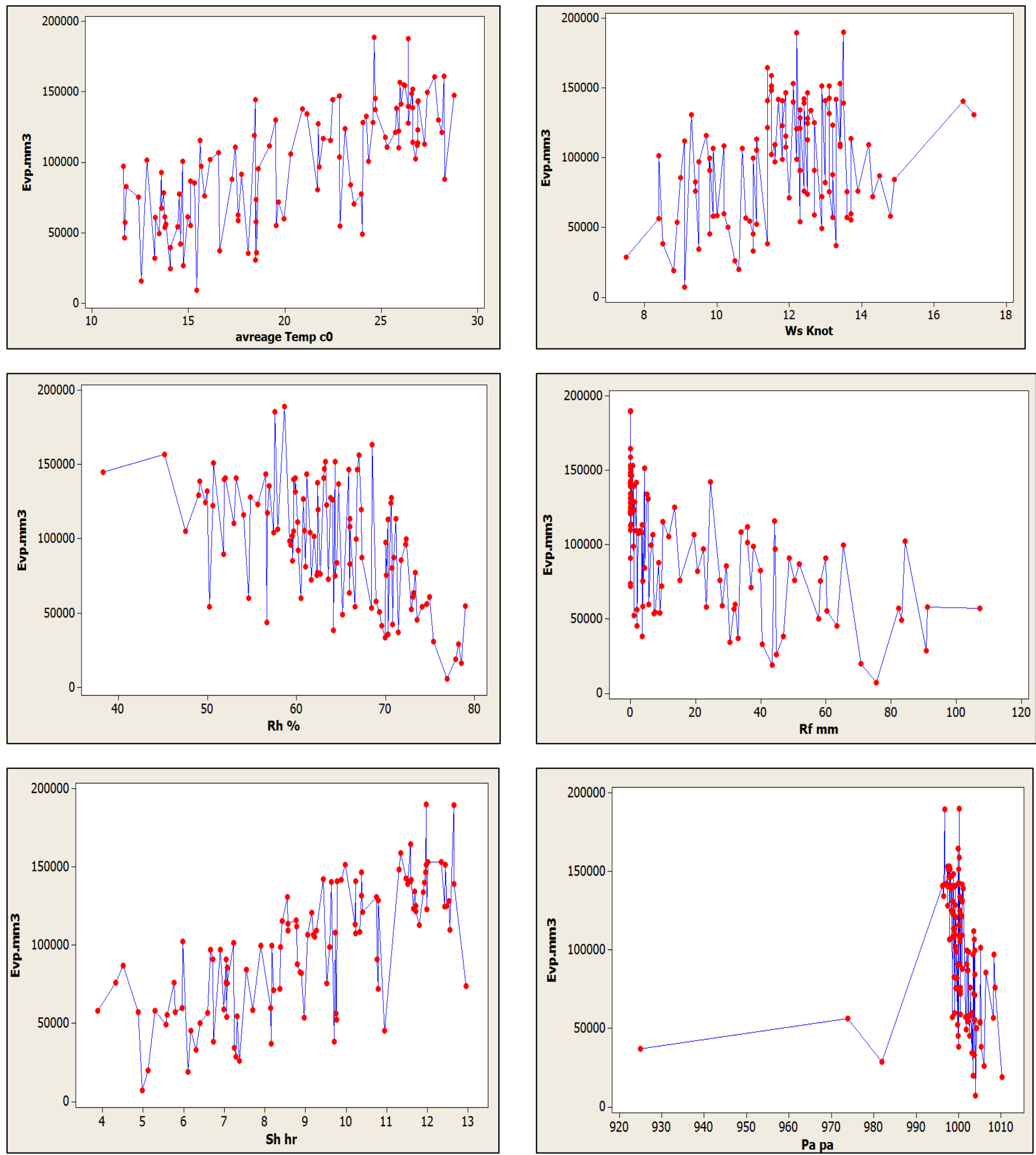

Figure 6 Monthly variations of the climatic parameter and the evaporation for 2001 to 2009. at Omar Muktar Open Reservoir. 
$80 \%$ of the whole data was chosen for training the Evp. models and the remaining data used for testing the models. Multiple liner regression (MLR) was employed by MINITAB (Ver.16) software package to develop the (MLR) pan evaporation models. The performance including both the accuracy and agreement of the MLR methods were evaluated through different input combinations see Table 3. The comparative statistics i.e, MAPE, $95 \%$, and E, used to illustrate the performance of proposed MLR functions and the best performance was compared with the RSM, and ANN models. Is clear from the Table 3 that the models with full weather inputs have the best accuracy.

Table 3. Error statistics for input combinations using MLR model in test and validation stage.

\begin{tabular}{|c|c|c|c|c|c|}
\hline Input combinations & $\begin{array}{c}\text { RSM } \\
\text { equations }\end{array}$ & МРЕ\% & $\mathbf{E}$ & $\begin{array}{l}\text { The Evp. } \\
\text { predicted } \\
\text { average }\end{array}$ & $95 \% \mathrm{CI}$ \\
\hline $\begin{array}{c}\text { Average } \\
\text { Temp }\end{array}$ & Evp $=28166.1+590.1$ average Temp +127 average Temp ${ }^{2}$ & 37.68 & 0.56 & 98384.74 & \\
\hline $\begin{array}{l}\text { Average Temp, } \\
\text { Rh }\end{array}$ & $\begin{aligned} \text { Evp }=96503+30135 & \text { average Temp }-38006 \mathrm{Rh} \\
& +40573 \text { average Temp } \\
& +16158 \mathrm{Rh}^{2} \\
& +17149 \text { averageTemp } \times R h\end{aligned}$ & 30.38 & 0.63 & 98287.13 & \\
\hline $\begin{array}{c}\text { Average Temp, } \\
\text { Rh, Ws }\end{array}$ & 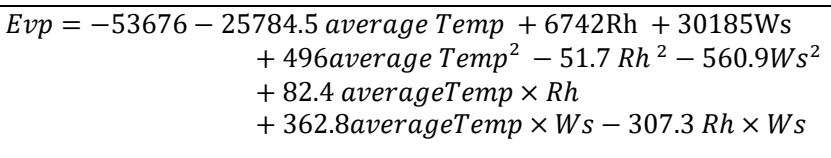 & 29.40 & 0.67 & 98006.74 & \\
\hline $\begin{array}{c}\text { Average Temp, } \\
\text { Rh, Ws, Sh }\end{array}$ & $\begin{aligned} \text { Evp }=-120380- & 64350 \text { average Temp }+6627 \mathrm{Rh}+29935 \mathrm{Ws} \\
& +104232 \text { Sh }+228 \text { average Temp }{ }^{2}-52 \mathrm{Rh}^{2} \\
& -423 \mathrm{Ws}^{2}-3341 \mathrm{Sh}^{2} \\
& +443 \text { averageTemp } \times \text { Rh } \\
& +10095 \text { averageTemp } \times W s \\
& +1948 \text { averageTemp } \times \text { Sh }-259 R h \times W s \\
& -858 R h \times \text { Sh }-2181 W S \times S h\end{aligned}$ & 25.60 & 0.71 & 98264.62 & \\
\hline
\end{tabular}

Average Temp,

Rh, Ws, Sh, Pa
$E v p=-96000383-48835$ average Temp $+265403 \mathrm{Rh}$

+ 956470Ws + $1044870 S h+157108 \mathrm{~Pa}$

$=+223$ average Temp ${ }^{2}-29 R h^{2}-115 W s^{2}$

$-3145 S h^{2}-61 \mathrm{~Pa}^{2}+365$ averageTemp $\times R h$

+1875 averageTemp $\times W s$

+1059 averageTemp $\times$ Sh

-13 averageTemp $\times P a-160 R h \times W S$

$-1009 R h \times S h-259 R h \times P a-4828 W s \times S h$

$-934 W s \times P a-882 S h \times P a$

\subsection{0 \\ 0.72 \\ 97925.05}

0.73

97794.92
Rh, Ws, Sh, Pa, Rf

$$
\begin{aligned}
& \text { Evp }=-49477746-302619 \text { average Temp }+66184 \mathrm{Rh} \\
& +751764 \mathrm{Ws}+694092 \mathrm{Sh}+87555 \mathrm{~Pa} \\
& -39888 R f+272 \text { average Temp }{ }^{2}-45 R h^{2} \\
& +103 W s^{2}-2162 S h^{2}-38 P a^{2}+5 R f^{2} \\
& +598 \text { averageTemp } \times R h \\
& +1908 \text { averageTemp } \times W s \\
& +1567 \text { averageTemp } \times \text { Sh } \\
& +221 \text { averageTemp } \times P a \\
& -63 \text { averageTemp } \times R f+32 R h \times W s \\
& -1220 R h \times S h-64 R h \times P a+14 R h \times R f \\
& -3828 W s \times S h-755 W s \times P a+12 W s \times R f \\
& -565 S h \times P a+438 S h \times R f+37 R f \times P a
\end{aligned}
$$




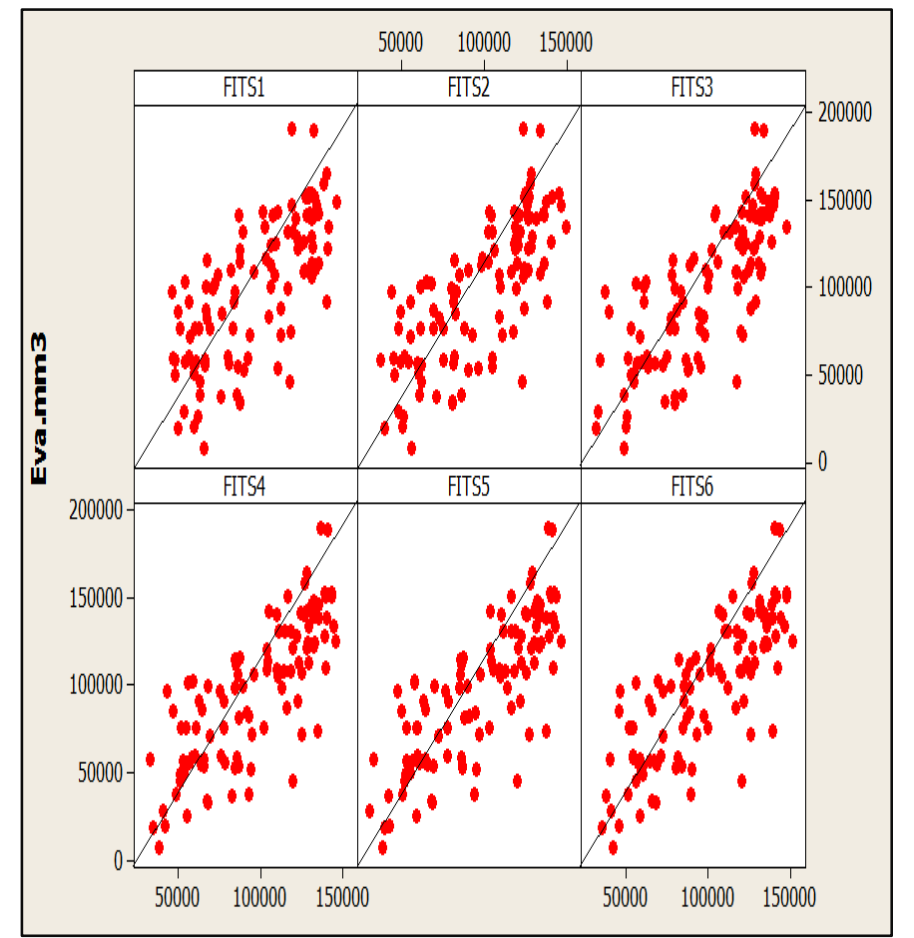

Figure7. The observed and estimated pan evaporation using MLR (2001 to 2009) at Omar Muktar Open Reservoir.

A response surface (RSM) function was proposed with simple formulation to estimate the pan evaporations using climatic input variables. The RSM function was extended on order of polynomial functions based on input variables more than two. In this approach, the polynomial functions were simply and directly calibrated based on the observed climatic data and relative of evaporation data for each input combination. RSM models were

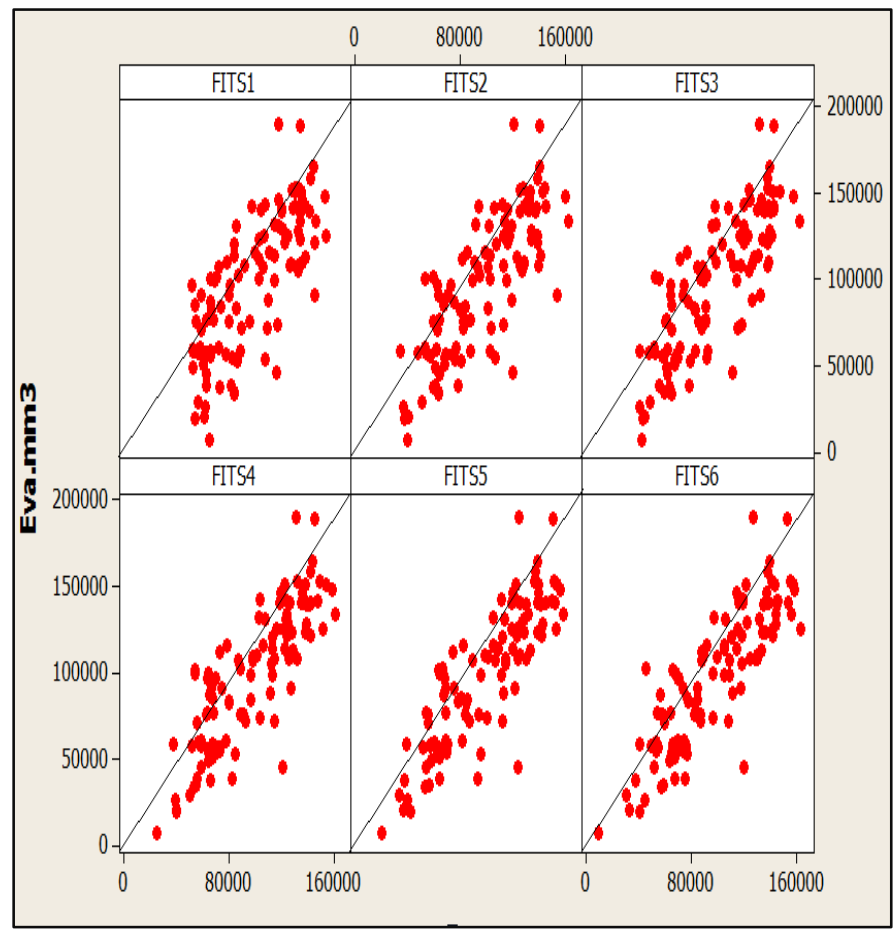

Figure 8. The observed and estimated pan evaporation using RSM (2001 to 2009) at Omar Muktar Open Reservoir

compared with each other based on input variables combination see Table 4. These result revealed that the RMS models were much simpler and could successfully use in estimating monthly pan evaporations. The full input RSM models provided results close to observed pan evaporation based on E, MAPE\%, 9\%CI, see Figure 8 .

Table 4. Error statistics for input combinations using RSM model in test and validation stage.

\begin{tabular}{|c|c|c|c|c|c|}
\hline $\begin{array}{c}\text { Input } \\
\text { combinations }\end{array}$ & $\begin{array}{c}\text { RSM } \\
\text { equations }\end{array}$ & MPE\% & $\mathrm{E}$ & $\begin{array}{l}\text { The Evp. } \\
\text { predicted } \\
\text { average }\end{array}$ & $95 \% \mathrm{CI}$ \\
\hline $\begin{array}{l}\text { Average } \\
\text { Temp }\end{array}$ & $\begin{aligned} E v p=28166.1 & +590.1 \text { average Temp } \\
& +127 \text { average Temp }\end{aligned}$ & 37.68 & 0.56 & 98384.74 & \\
\hline $\begin{array}{l}\text { Average } \\
\text { Temp, } \\
\text { Rh }\end{array}$ & $\begin{aligned} E v p=96503+ & 30135 \text { average Temp } \\
& -38006 \mathrm{Rh} \\
& +40573 \text { average Temp } \\
& -16158 \text { Rh }^{2} \\
& +17149 \text { averageTemp } \times R h\end{aligned}$ & 30.38 & 0.63 & 98287.13 & 90367--105764 \\
\hline
\end{tabular}


L.S. Bentaher / Advances in Science, Technology and Engineering Systems Journal Vol. 2, No. 2, 19-29 (2017)

\begin{tabular}{|c|c|c|c|c|c|}
\hline $\begin{array}{c}\text { Input } \\
\text { combinations }\end{array}$ & $\begin{array}{c}\text { RSM } \\
\text { equations }\end{array}$ & MPE\% & $\mathrm{E}$ & $\begin{array}{c}\text { The Evp. } \\
\text { predicted } \\
\text { average }\end{array}$ & $95 \% \mathrm{CI}$ \\
\hline $\begin{array}{c}\text { Average } \\
\text { Temp, } \\
\text { Rh, Ws }\end{array}$ & $\begin{aligned} \text { Evp }=-53676 & -25784.5 \text { average Temp } \\
& +6742 \mathrm{Rh}+30185 \mathrm{Ws} \\
& +496 \text { average Temp } \\
& -51.7 \text { Rh }^{2}-560.9 \mathrm{Ws}^{2} \\
& +82.4 \text { averageTemp } \times \text { Rh } \\
& +362.8 \text { averageTemp } \times W s \\
& -307.3 \text { Rh } \times W s\end{aligned}$ & 29.40 & 0.67 & 98006.74 & \\
\hline $\begin{array}{c}\text { Average } \\
\text { Temp, } \\
\text { Rh, Ws, Sh }\end{array}$ & $\begin{array}{rl}\text { Evp }=-120 & 380-64350 \text { average Temp } \\
& +6627 \mathrm{Rh}+29935 \mathrm{Ws} \\
& +104232 \text { Sh } \\
& +228 \text { average Temp } \\
& -52 \text { Rh }^{2}-423 \mathrm{Ws}^{2} \\
& -3341 \mathrm{Sh}^{2} \\
& +443 \text { averageTemp } \times \text { Rh } \\
& +10095 \text { averageTemp } \times W s \\
& +1948 \text { averageTemp } \times S h \\
& -259 \text { Rh } \times W s \\
& -858 R h \times S h \\
& -2181 W s \times S h\end{array}$ & 25.60 & 0.71 & 98264.62 & \\
\hline $\begin{array}{c}\text { Average } \\
\text { Temp, } \\
\text { Rh, Ws, Sh, } \\
\text { Pa }\end{array}$ & $\begin{array}{rl}\text { Evp }=-960003 & 83-48835 \text { average Temp } \\
& +265403 \mathrm{Rh}+956470 \mathrm{Ws} \\
& +1044870 \mathrm{Sh}+157108 \mathrm{~Pa} \\
& =+223 \text { average Temp } \\
& -29 \mathrm{Rh}^{2}-115 \mathrm{Ws}^{2} \\
& -3145 \mathrm{Sh}^{2}-61 \mathrm{~Pa}^{2} \\
& +365 \text { averageTemp } \times \text { Rh } \\
& +1875 \text { averageTemp } \times W s \\
& +1059 \text { averageTemp } \times \text { Sh } \\
& -13 \text { averageTemp } \times \mathrm{Pa} \\
- & 160 \mathrm{Rh} \times \mathrm{Ws} \\
-1009 \mathrm{Rh} \times & \mathrm{Sh}-259 \mathrm{Rh} \times \mathrm{Pa} \\
& -4828 \mathrm{WS} \times \mathrm{Sh} \\
& -934 \mathrm{Ws} \times \mathrm{Pa} \\
& -882 \mathrm{Sh} \times \mathrm{Pa}\end{array}$ & 23.30 & 0.72 & 97925.05 & \\
\hline
\end{tabular}




\begin{tabular}{|c|c|c|c|c|c|}
\hline $\begin{array}{c}\text { Input } \\
\text { combinations }\end{array}$ & $\begin{array}{c}\text { RSM } \\
\text { equations }\end{array}$ & MPE\% & $\mathrm{E}$ & $\begin{array}{l}\text { The Evp. } \\
\text { predicted } \\
\text { average }\end{array}$ & $95 \% \mathrm{CI}$ \\
\hline $\begin{array}{c}\text { Average } \\
\text { Temp, } \\
\text { Rh, Ws, Sh, } \\
\text { Pa, Rf }\end{array}$ & $\begin{array}{rl}\text { Evp }=-49477 & 46-302619 \text { average Temp } \\
& +66184 \mathrm{Rh}+751764 \mathrm{Ws} \\
& +694092 \mathrm{Sh}+87555 \mathrm{~Pa} \\
& -39888 R f \\
& +272 \text { average Temp } \\
& -45 \mathrm{Rh}^{2}+103 \mathrm{Ws}^{2} \\
& -2162 \mathrm{Sh}^{2}-38 \mathrm{~Pa}^{2}+5 R f^{2} \\
& +598 \text { averageTemp } \times R h \\
& +1908 \text { averageTemp } \times W s \\
& +1567 \text { averageTemp } \times S h \\
& +221 \text { averageTemp } \times P a \\
& -63 \text { averageTemp } \times R f \\
& +32 \text { Rh } \times W s \\
& -1220 R h \times \text { Sh }-64 R h \times P a \\
& +14 R h \times R f \\
& -3828 W s \times S h \\
& -755 W s \times P a+12 W s \times R f \\
& -565 S h \times P a+438 S h \times R f \\
& +37 R f \times P a\end{array}$ & 21.53 & 0.73 & 97794.92 & \\
\hline
\end{tabular}

The ANN models were trained using Bayesian Regularization (BR) and Levenberg-Marquardt (LM) algorithms. In ANN models the number of neurons in the hidden layer were found by a trial and error procedure. The activation functions used for the hidden and output layers were the 'logsig' and 'purelin' functions, respectively. Table 5 showing the structure of ANN models according to the input combination, moreover the models were improved by the accuracy with respect to MAPE\%,E,CI $95 \%$. ANN $(6,10,1)$ model indicates model having 6,10 and 1 for the input, hidden and output, respectively and the data divided in to (86 values for model training,5 values for model validation,5 values for model testing ). Over all ANN showing best prediction for all input combination in both test and validation periods. Figure 10 showing the comparison between the predicted and observed evaporation data.

The best architecture was obtained for ANN evaporation model (ANN 6-10-1) has been selected based on minimum value of MSE and maximum value of $\mathrm{E}$. The output from the best selected architecture for the ANN-6 model was validated using the testing data set (2008 to 2009). The objective of the validation process is to investigate the ability of the model to work with an independent data series that have not been used in training of the evaporation model.

In this study, models with different local input combinations were compared with each other in estimating Evp for (2001-2009). The results showed that the models with more inputs generally have better accuracies.

The ANN model performed superior to the other models in predicting monthly Evp at most inputs used, with respect to
MAPE\%, E and 95CI \%. ANN methods provide the best estimations, and can be used successfully also RSM . These two new methods provide a promising new approach for evaporation estimation in semi-arid climates. The best performance results obtained presented at Table 6 also figures 10,11,12and 13.

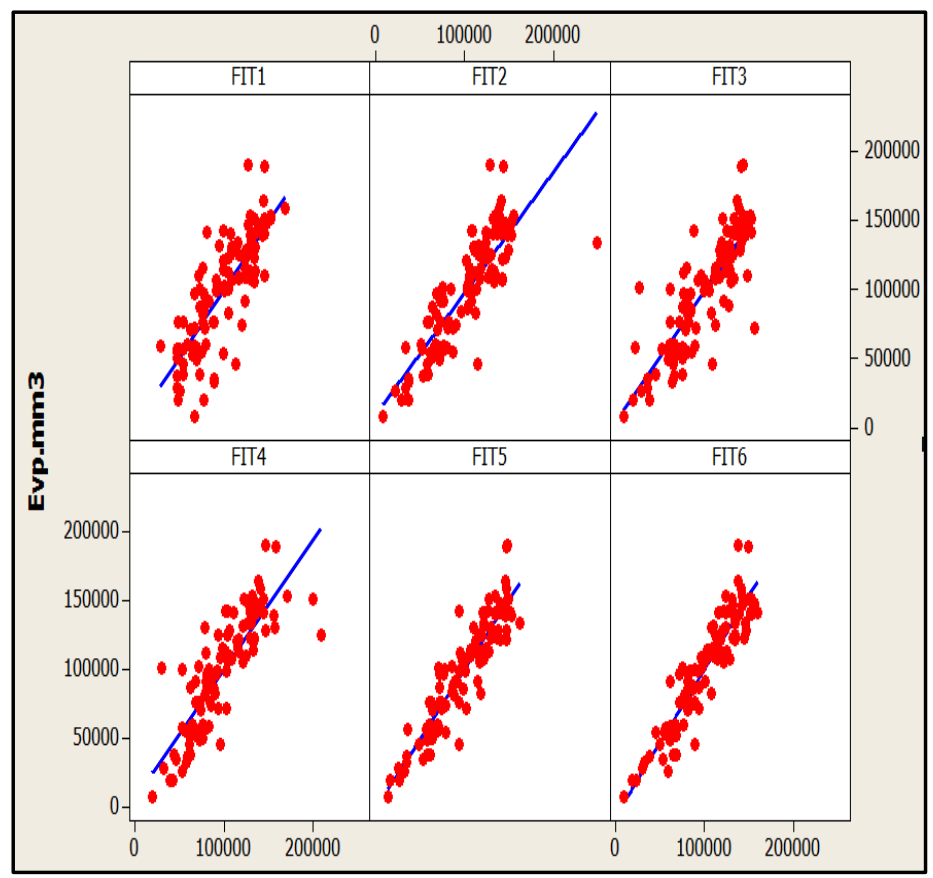

Figure 9. The observed and estimated pan evaporation using ANN (2001 to 2009) at Omar Muktar Open Reservoir

Table 5. Error statistics for input combinations using ANN models in test and validation stage. 
L.S. Bentaher / Advances in Science, Technology and Engineering Systems Journal Vol. 2, No. 2, 19-29 (2017)

\begin{tabular}{|c|c|c|c|c|c|}
\hline Input combinations & $\begin{array}{l}\text { ANN Model } \\
\text { architecture }\end{array}$ & МРE\% & $\mathbf{E}$ & $\begin{array}{c}\text { The Evp. } \text { predicted } \\
\text { average }\end{array}$ & $95 \% \mathrm{CI}$ \\
\hline Average Temp & ANN1 $(1,10,1)$ & 32.85 & 0.66 & 98294.44 & \multirow{6}{*}{ 90367--105764 } \\
\hline $\begin{array}{c}\text { Average Temp, } \\
\text { Rh }\end{array}$ & ANN $2(2,10,1)$ & 18.99 & 0.71 & 100922.04 & \\
\hline $\begin{array}{c}\text { Average Temp, } \\
\text { Rh, Ws }\end{array}$ & ANN3 $(3,10,1)$ & 19.86 & 0.70 & 99092.96 & \\
\hline $\begin{array}{c}\text { Average Temp, } \\
\text { Rh, Ws, Sh }\end{array}$ & ANN $4(4,10,1)$ & 22.08 & 0.71 & 97280.65 & \\
\hline $\begin{array}{l}\text { Average Temp, } \\
\text { Rh, Ws, Sh, Pa }\end{array}$ & ANN5 $(5,10,1)$ & 14.57 & 0.85 & 98217.31 & \\
\hline $\begin{array}{c}\text { Average Temp, } \\
\text { Rh, Ws, Sh, Pa, Rf }\end{array}$ & ANN $6(6,10,1)$ & 13.90 & 0.86 & 97350.46 & \\
\hline
\end{tabular}

Table 6. Error statistics for best performance of ANNs, MLR and RSM models in test and validation stage.

\begin{tabular}{cccc|c}
\hline The model & MPE\% & E & The average predicted Evp. mm3 & $\begin{array}{c}\text { 95\% CI } \\
\text { Observed Evp mm3 }\end{array}$ \\
\hline MLR -6 & 29.46 & 0.65 & 97758.85 & \\
\hline RSM -6 & 21.53 & 0.73 & 97794.92 & \\
\hline
\end{tabular}

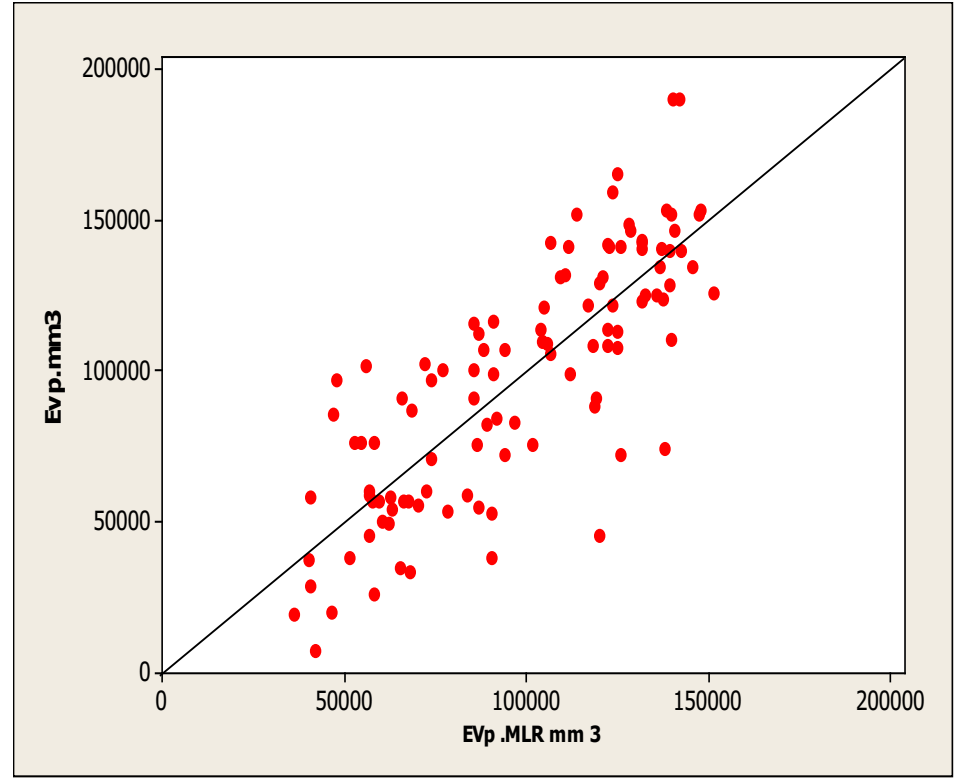

Figure 10. Comparison of the observed and estimated Evp using MLR-6 model during the training and testing period.

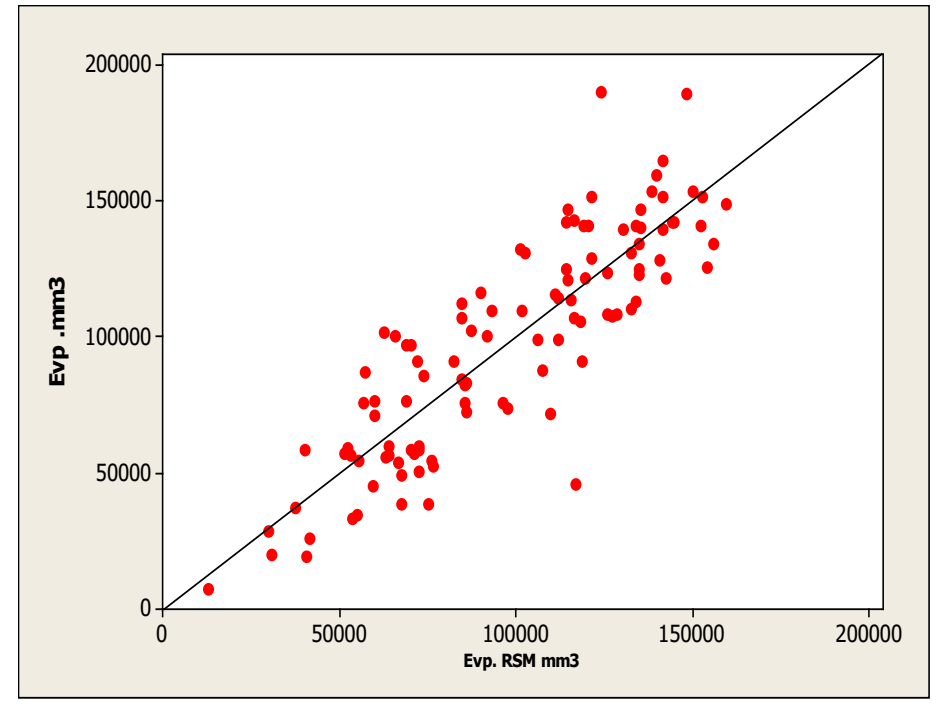

Figure 11. Comparison of the observed and estimated Evp using RSM-6 model during the training and testing period. 


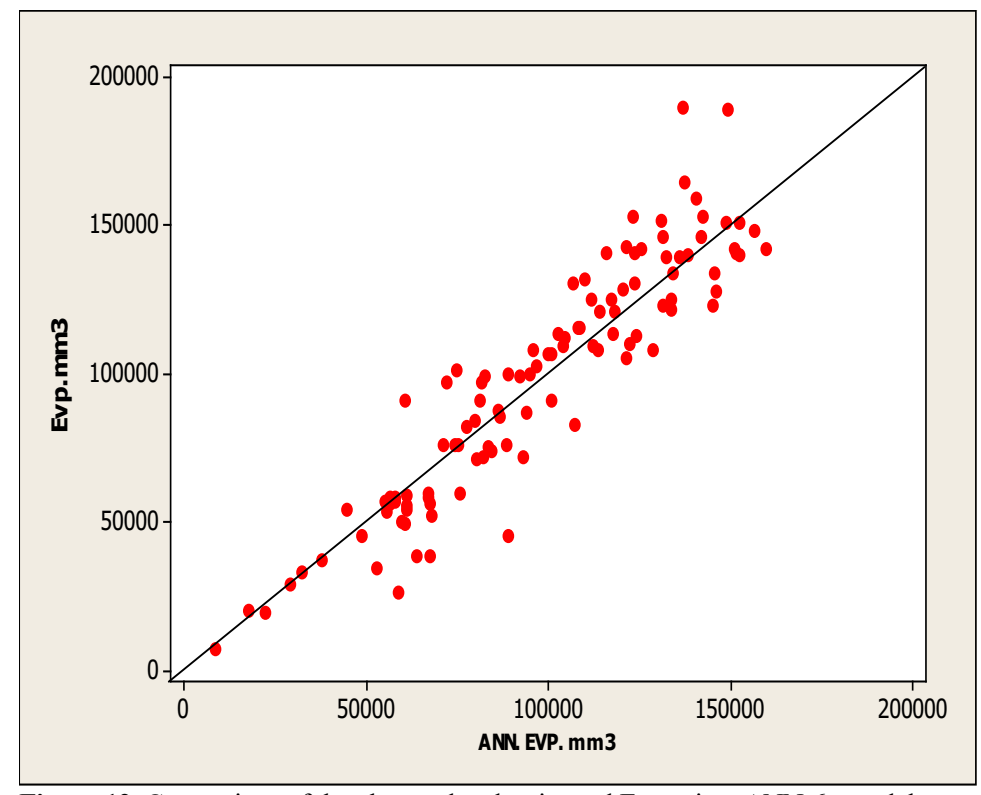

Figure 12. Comparison of the observed and estimated Evp using ANN-6 model during the training and testing period.

Noted that, Some of unusual observation evaporation value, all models yelled a results lower than it, also closed together, that mean there was a problem when measured these value see Figure 13 highlighted by red circle ( 2003, 2004, 2007 ).

\section{4- Conclusion}

This study investigated and compared the abilities of three different soft computing techniques, MLR, RSM, and ANN in modeling Evp. using different climatic input combinations of (average Temp, Rh, Sh, Ws , Pa and Rf). The climatic data obtained from Omar Muktar Open Reservoir (zone of semi-arid climate) were used for training and testing Evp. models. The models with different local input combinations were compared with each other in estimating monthly Evp. The results showed that the models with more inputs generally have better accuracies and the ANN model performed superior to the other models in predicting monthly Evp with high $\mathrm{E}=0.86$ and lowest MAPE= $13.9 \%$ and have predicted mean within the range of observed $95 \mathrm{CI} \%$, also, the RSM model performed good . In summary, it was revealed in this study that the ANN and RSM models were appropriate for predicting monthly Evp using climatic inputs in semi-arid climate. The present applications can be practically adopted in the field of water resources management for accurately mapping regional distributions of evaporation and related water resource open storages.

\section{REFERENCES}

[1] Fekih,M., Bourabaa, A. and Mohamed, S. ,2013, Evaluation of two methods for estimation of evaporation from Dams water in arid and semi-arid areas in Algeria, International Journal of Application or Innovation in Engineering \& Management (IJAIEM), 2, 376-381, ISSN 2319 - 4847.

[2] Benzaghta, M. A., Mohammed, T. A. and Ekhmaj, A. I., 2012, Prediction of Evaporation from Algardabiya Reservoir, Libyan Agriculture Research Center Journal International ,3,120-128, ISSN 2219-4304.

[3] Dalkiliç, Y., Okkan, U. and Baykan, N., 2014, Comparison of Different Ann Approaches in Daily Pan Evaporation Prediction, Journal of Water Resource and Protection, 6, 319-326. http://dx.doi.org/10.4236/jwarp.2014.64034.

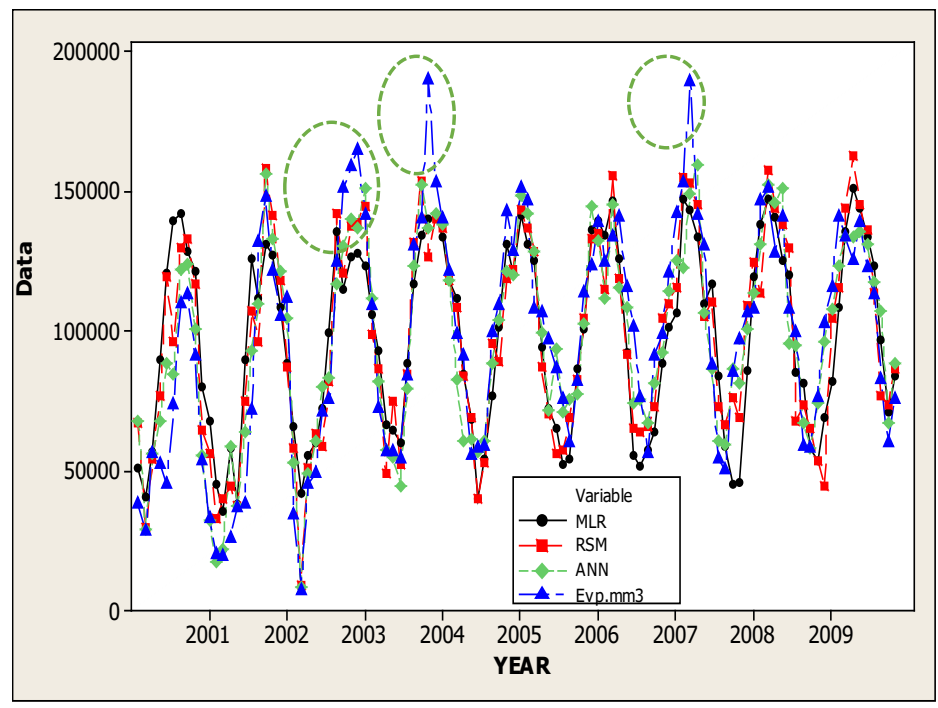

Figure 13. monthly evaporation values observed and predicted by ANN-6, RSM6, MLR-6 model for (2001 to 2009 ) at Omar Muktar Open Reservoir.

[4] Goyal, M. K., Bharti, B., Quilty, J. c, Adamowski, J. and Pandey, A. ,2014, Modeling of daily pan evaporation in sub tropical climates using ANN, LSSVR, Fuzzy Logic, and ANFIS, Expert Systems with Applications, 41 , $5267-$ 5276 .

[5] Behrooz Keshtegar, and Ozgur Kisi , 2016, A nonlinear modelling-based high-order response surface method for predicting monthly pan evaporations, Hydrol. Earth Syst. Sci. Manuscript under review , CC-BY 3.0 License.

[6] Wang, L., Kisi, O., Z.-Kermani, M., and, Gan, Y.,2016, Comparison of six different soft computing methods in modeling evaporation in different climates, Hydrol. Earth Syst. Sci. Manuscript under review. CC-BY 3.0 License.

[7] Benzaghta, M. A. , Mohammed, T. A., Ghazali, A.H. and Soom, M. A.,2012 Prediction of evaporation in tropical climate using artificial neural network and climate based models, Scientific Research and Essays ,36, 3133-3148, ISSN 1992-2248.

[8] Alsanusi, S., Bentaher, L. ,2015, Prediction of Compressive Strength of Concrete from Early Age Test Result Using Design of Experiments (RSM)", International Journal of Civil, Environmental, Structural, Construction and Architectural Engineering, 9 ,1522-1526.

[9] Elmazoghi, H. G., Karakale, V. and Bentaher, L., 2016, Comparison of neural networks and neuro-fuzzy computing techniques for prediction of peak breach outflow, Journal of Hydroinformatics , 18,724-740. 